\title{
Prayer and Health: Review, Meta-Analysis, and Research Agenda
}

\author{
Kevin S. Masters · Glen I. Spielmans
}

Published online: 25 July 2007

(C) Springer Science+Business Media, LLC 2007

\section{Erratum to: J Behav Med} DOI 10.1007/s10865-007-9106-7

The original version of this article unfortunately contained a mistake. The presentation of Fig. 1 was incorrect. The corrected presentation is given below.

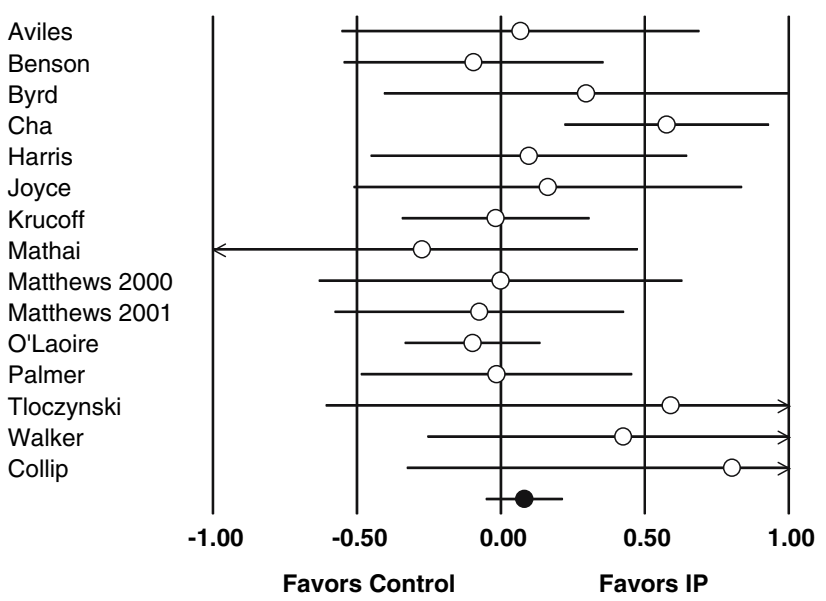

Fig. 1 Forest plot of effect sizes and confidence intervals for individual studies and overall
The online version of the original article can be found under doi: 10.1007/s10865-007-9106-7.

\section{K. S. Masters $(\square)$}

Department of Psychology, Syracuse University, 430 Huntington

Hall, Syracuse, NY 13244-2340, USA

e-mail: kemaster@syr.edu

G. I. Spielmans

Department of Psychology, Metropolitan State University,

St. Paul, MN, USA 